\title{
Enerji Tüketimi ve Ekonomik Büyüme İlişkisi: G7 Ülkeleri Örneği
}

\section{Emrullah METE ${ }^{1}$}

\begin{tabular}{|c|c|c|}
\hline $\begin{array}{c}\text { Geliş Tarihi/ Receiv } \\
17.05 .2021 \\
\end{array}$ & $\begin{array}{c}\text { Kabul Tarihi/ Accepte } \\
17.08 .2021 \\
\end{array}$ & $\begin{array}{r}\text { Yayın Ta } \\
15 .\end{array}$ \\
\hline \multicolumn{3}{|c|}{ Citation/Atıf: Mete E., (2021), Enerji Tüketimi ve Ekonomik Büyüme İlişkisi: G7 Ülkeleri Örneği, Atatürk } \\
\hline $\begin{array}{l}\text { Üniversitesi } \quad \text { Iktisadi } \\
\text { https://doi.org/10.16951/atau }\end{array}$ & $\begin{array}{c}\text { ve İdari Bilimler Dergisi, } \\
\text { uniiibd.938207 }\end{array}$ & 35(4): $\quad$ Sayfa: $\quad$ 1481-1495, \\
\hline
\end{tabular}

Öz: Enerji tüketimi ile ekonomik büyüme arasındaki ilişkinin araştırıldığı bu çalışmada G7 ülkelerinin 1993-2018 dönemine ait veriler kullanılmıştır. Ekonomik büyüme, enerji tüketimi, sera gazı emisyonu ve ticari açıklık değerlerinin analize dahil edildiği çalışmada Gengenbach, Urbain and Westerlund panel eşbütünleşme analizinden yararlanılmıştır. Ayrıca, uzun dönemli ilişkinin tahmini için ortalama grup dinamik en küçük kareler (DOLSMG) yöntemi ile uzun ve kısa dönemli ilişkinin tahmini için genişletilmiş ortalama grup tahmincisi (AMG) yöntemi kullanılmıştır Eşbütünleşme analizi sonuçlarına göre enerji tüketimi, ticari açıklık, sera gazı emisyonu ve ekonomik büyümenin eşbütünleşik olduğu tespit edilmiştir. Ayrıca, uzun dönemli ilişkinin tahmini için yapılan ortalama grup dinamik en küçük kareler (DOLSMG) yöntemi sonuçlarına göre uzun dönemde bağımsız değişkenlerin enerji tüketimini etkilediği sonuçlarına ulaşılmıştır. Son olarak, uzun ve kısa dönemli ilişkinin tahmini için kullanılan AMG yöntemi sonuçlarına göre, i) ticari açıklığın istatistiksel olarak anlamsız olduğu, ii) sera gazı emisyonundaki ve ekonomik büyümedeki artıșın enerji tüketimini artırdığı tespit edilmiștir.

Anahtar Kelimeler: Enerji tüketimi, Ekonomik büyüme, Sera gazı emisyonu, G7 Ülkeleri

The Relationship Between Energy Consumption and Economic Growth: The Case of G7 Countries

Abstract: In this study, which investigates the relationship between energy consumption and economic growth, the data of the G7 countries from 1993 to 2018 were used. Gengenbach, Urbain and Westerlund panel cointegration analysis was used in the study in which economic growth, energy consumption, greenhouse gas emissions and trade openness values were included in the analysis. In addition, the mean group dynamic least squares (DOLSMG) method was used for the estimation of the long-term relationship, and the extended mean group estimator $(A M G)$ method was used for the estimation of the long and short-term relationship. According to the results of the cointegration analysis, it has been determined that energy consumption, trade openness, greenhouse gas emissions and economic growth are cointegrated. According to the results of the average group dynamic least squares (DOLSMG) method for the estimation of the long-term relationship, it was concluded that the independent variables affect the energy consumption in the long run. Finally, according to the results of the AMG method used to estimate the long-and shortterm relationship, it was determined that i) trade openness was statistically insignificant, ii) the increase in greenhouse gas emissions and economic growth increased energy consumption.

Keywords: Energy Consumption, Economic Growth, Greenhouse Gas Emission, G7 Countries JEL Codes: C23, O13, O40, Q43

${ }^{I}$ Dr. Öğr. Üyesi, Giresun Üniversitesi, Görele Uygulamalı Bilimler Yüksekokulu, Lojistik Yönetimi Bölümü,mtemrullah@gmail.com,https://orcid.org/0000-0003-2240-9248 
Enerji Tüketimi ve Ekonomik Büyüme İlişsisi: G7 Ülkeleri Örneği

\section{Background}

\section{EXTENDED ABSTRACT}

Energy, which is seen as a component of production factors such as capital and labor in production processes, especially for manufacturing sectors in both developed and developing countries, is the main determinant of economic development and social stability. With the industrial revolution, energy use has increased significantly, and energy has been identified as an important factor in explaining long-term growth while production has increased, in addition to capital and labor. This has shown that industrialization creates interdependence between energy and economic growth. The energy crisis that broke out in the 1970s showed that energy resources were both exhaustible and indispensable for the production process and output. As a matter of fact, the demand for energy is increasing day by day due to socio-economic development and rapid population growth. The theoretical literature is built on four basic hypotheses for the relationship between energy and economic growth. These hypotheses are called growth hypothesis, conservation hypothesis, neutrality hypothesis and feedback hypothesis. The validity of the conservation hypothesis has been tested for the G7 countries in the study, which deals with whether economic growth affects energy consumption or not.

\section{Purpose}

G7 countries are the countries that direct the international economy, with a significant portion of the global income, and they have been the leading group in finding solutions to the oil crisis that emerged in 1973. The propose of this study is to investigate the relationship between energy consumption, economic growth, trade openness and greenhouse gas emissions in G7 countries.

\section{Method}

In this study, which examines the relationship between energy consumption and economic growth, the data of the G7 countries for the period 1993-2018 are used. In the study where energy consumption is taken as the dependent variable, trade openness, economic growth and greenhouse gas emissions are included in the analysis as independent variables. Trade openness and economic growth data from WDI. Greenhouse gas emission data from OECDstat and energy consumption data from IEA. Gengenbach, Urbain and Westerlund panel cointegration test was used in the study. Then, the average group dynamic least squares (DOLSMG) method was used to estimate the longterm relationship. Finally, the expanded Augmented Mean Group Estimator (AMG) method was used for the estimation of the long and short term relationship, namely for the panel error correction model.

\section{Conclusions}

In the study in which cointegration analysis is preferred, independent variables affect energy consumption in the long run. No statistically significant relationship was found between trade openness and energy consumption in the short term. It is concluded that in the short term, increases in greenhouse gas 
emissions and economic growth increase energy consumption. The positive effect of economic growth on energy consumption supports the conservation hypothesis in the literature.

\section{Giriş}

Küreselleşme olgusu gelişmiş ve gelişmekte olan ülkeleri sosyo-kültürel, politik ve ekonomik düzlemde bütünleştirmekle kalmamış aynı zamanda rekabeti de yoğunlaştırmıştır. Ülkeler refah düzeyini artırma, sosyo-ekonomik gelişim ve beşeri kalkınmalarını iyileştirme hedefi konusunda rekabet halindedir. Söz konusu hedeflere ulașabilmek için ekonomik büyümenin sürdürülebilir olması gerekmekte ve bu sürdürülebilirlik için de enerji önemli bir itici güç kabul edilmektedir.

Hem gelişmiş hem de gelişmekte olan ülkelerde özellikle imalat sektörleri için üretim süreçlerinde sermaye ve emek gibi üretim faktörlerinin bir bileşeni olarak görülen enerji, ekonomik kalkınmanın ve sosyal istikrarın temel belirleyicisidir. Sanayi devrimi ile birlikte enerji kullanımı önemli ölçüde artmış, üretim artarken uzun vadeli büyümenin açıklanmasında sermaye ve emeğe ek olarak enerji önemli bir faktör olarak belirlenmiștir. Bu durum sanayileşmenin enerji ile ekonomik büyüme arasında karşılıklı bağımlılık oluşturduğunu göstermiştir. 1970'li yıllarda patlak veren enerji krizi, enerji kaynaklarının hem tükenebilir olduğunu hem de üretim süreci ve çıktı için olmazsa olmaz boyutta önemli olduğunu göstermiştir. Nitekim, sosyo-ekonomik gelişme ve hızlı nüfus artışı nedeniyle enerjiye olan talep gün geçtikçe artmaktadır. Genel bir tanımla enerji talebi, tüketim açısından insanların günlük ihtiyaçları için, üretim açısından ise mal ve hizmet üretimi için talep edilen enerji miktarıdır (Sweeney, 2000: 5). $\mathrm{Bu}$ açıdan enerji, günlük ihtiyaçlar ve üretim süreci için zorunlu ve vazgeçilmez bir unsurdur.

Hem enerji tüketimi hem de ekonomik büyüme birbirleri için sebep ve sonuç olarak işleyebilir. Enerji, her türlü üretim faaliyeti için hayati önem taşır ve ekonomik büyümenin ana itici gücü olarak kabul edilir. Öte yandan, ekonomik büyümenin artmasıyla birlikte enerji talebi de dahil olmak üzere mal ve hizmetlere olan talep artacaktır. Sadorsky (2012), enerji tüketimi ile ekonomik büyümenin genellikle zaman içinde birlikte hareket ettiğini belirtmektedir. $\mathrm{Bu}$ birlikte hareketi ise, ekonomik büyümedeki artışın enerji tüketimi ve ithalatını artırdığı, artan enerji tüketiminin daha fazla ihracat ve ithalata yol açarak ekonomik büyümeyi artırdığ 1 şeklinde yorumlamıştır. Teorik literatür enerji ile ekonomik büyüme arasındaki ilişki için dört temel hipotez üzerine kurulmuştur. Bu hipotezler büyüme hipotezi, koruma hipotezi, tarafsızlık hipotezi ve geri besleme hipotezi olarak adlandırılmaktadır. Büyüme hipotezine göre enerjiye yönelik tüketim girdileri doğrudan ekonomik büyümeyi desteklemekte ve üretim sürecinde emek ve sermayenin tamamlayıcısı olarak ifade edilmektedir (Ebohon, 1996: 452; Templet, 1999: 229; Apergis ve Payne, 2009: 211). Dolayısiyla bu 
hipoteze göre enerji tüketimindeki bir artı̧̧ ekonomik büyümeyi artırmaktadır. Büyüme hipotezinin aksine koruma hipotezine göre, gelir seviyesindeki bir artış, daha yüksek enerji tüketimine yol açar. Ekonomik büyümeden enerji tüketimine doğru nedensel ilişki bu teorinin ana düşüncesini ortaya koymaktadır. Tarafsızlık hipotezi, enerji girdilerinin bir ülkenin ekonomik kalkınmasında küçük bir rol oynadığını ve ekonomik büyümeyi önemli ölçüde etkilemediğini varsayar. Diğer hipotezlerin aksine bu hipoteze göre enerji tüketimi ve ekonomik büyüme birbirine bağımlı değildir (Squalli, 2007: 1193). Son olarak, geri bildirim hipotezi, enerji tüketimi ile ekonomik büyümenin birbirine bağl1 olduğunu ve birbirini tamamlayıcı işlevi gördügünü öngörür. Bu durumda enerji tüketiminin artması ekonomik büyümede artışa, benzer şekilde ekonomik büyümedeki artış ise enerji tüketiminde artışa neden olmaktadır.

Ekonomik büyümenin enerji tüketimini etkileyip etkilemediği noktasında ele alınan bu çalışmada koruma hipotezinin geçerliliği $\mathrm{G} 7^{2}$ ülkeleri için sınanmıştır. G7 grubu küresel gelirin önemli bir kısmına sahip olmasıyla uluslararası ekonomiye yön veren ülkelerden oluşmaktadır. Bu grubun çalışmanın konusuyla da ilgili bir başka özelliği ise 1973 yılında ortaya çıkan petrol krizine çözüm üretme noktasında öncü grup olmasıdır (Konak, 2020, 237). $\mathrm{Bu}$ kapsamda çalışmanın giriş bölümünden sonraki bölümünde literatür taramasına yer verilmiş, üçüncü bölümde veri seti ve yöntem tanıtılmıştır. Dördüncü bölümde analiz bulgularının ardından son bölümde genel değerlendirme yapılmıştır.

\section{Literatür taraması}

Enerji tüketimi ile ekonomik büyüme arasındaki ilişkinin yönü konusunda dört farklı hipotezin geliştirilmesi, konunun ekonomi literatürünü oldukça meşgul etmesine neden olmuştur. Bu kapsamda özellikle son döneme ilişkin çalışmalara yer verilmiştir.

Rahman (2021) BRICS ve ASEAN ülke grupları için enerji tüketimi, uluslararası ticaret, doğrudan yabancı yatırımlar ve ekonomik büyüme arasındaki ilişkiyi 1990-2017 döneminde araştırmıştır. Panel eş bütünleşme, kantil regresyon ve nedensellik analizinin uygulandığı çalışma sonuçlarına göre enerji tüketiminin uzun dönemde ekonomik büyüme üzerinde pozitif etkili olduğu, ayrıca ekonomik büyüme ile enerji tüketimi arasında çift yönlü nedenselliğin olduğu tespit edilmiştir.

Canh vd. (2021) 1991-2014 döneminde küresel çapta 115 ülkeyi enerji tüketiminin belirleyicileri açısından değerlendirmişlerdir. Panel GMM modelinin uygulandığı çalışma sonuçlarına göre şehirleşmedeki artışın enerji tüketimini

${ }^{2}$ Almanya, ABD, Birleşik Krallık, Fransa, İtalya, Japonya, Kanada 
azalttığı, doğrudan yabanc1 yatırım girişlerinin enerji tüketimini artırdığı, sanayileşme ve ticari dışa açıklığın enerji kullanımını artırdığı tespit edilmiştir.

Erdoğan vd. (2020) enerji tüketimi ile ekonomik büyüme arasındaki ilişkiyi 1990-2014 dönemi için 8 MENA ülkesi için değerlendirmişlerdir. Panel nedensellik analizinin uygulandığı çalışma sonuçlarına göre enerji tüketiminin ekonomik büyümenin nedeni olduğu tespit edilmiştir.

Kahouli (2019) enerji tüketimi ile ekonomik büyüme arasındaki ilişki için 34 OECD ülkesini 1990-2015 döneminde incelemiştir. Panel GMM analizinin uygulandığı çalışma sonuçları geri besleme hipotezini desteklemekte yani ekonomik büyüme ile enerji tüketiminin birbirine bağımlı olduğunu, birinin artışının diğerinin artışına neden olduğunu desteklemektedir.

Altiner (2019) 1971-2014 dönemi verileriyle MINT ülkelerinde enerji tüketimi ile ekonomik büyüme arasındaki ilişkiyi incelemiştir. Panel nedensellik analizinin uygulandığı çalışma sonuçları panel geneli sonuçların ekonomik büyüme ile enerji tüketimi arasında nedensellik ilişkisinin olmadığını, ülkeler bazındaki sonuçların ise Meksika'da ekonomik büyümenin enerji tüketiminin nedeni olduğunu ifade etmektedir.

Muhammad (2019) enerji tüketimi, karbondioksit emisyonu $\left(\mathrm{CO}_{2}\right)$ ve ekonomik büyüme arasındaki ilişkiyi 2001-2017 döneminde gelişmiş ve gelişen ülkeler ile MENA ülkeleri açısından değerlendirmiştir. Bağımlı değişkenin ekonomik büyüme, enerji tüketimi ve $\mathrm{CO}_{2}$ emisyonu olarak alındığ 1 ve üç farklı modelin kurulduğu çalışmada Panel GMM analizi kullanılmıştır. Ekonomik büyümenin bağımlı değişken olduğu model sonuçları, gelişmiş ve gelişen ülkelerde enerji tüketimindeki artışla birlikte ekonomik büyümenin arttığ1 ancak MENA ülkelerinde azaldığı, $\mathrm{CO}_{2}$ emisyonunun ise gelişmiş ülkeler ve MENA ülkelerinde ekonomik büyümeyi pozitif etkilediği ancak gelişen ülkelerde ise negatif yönde etkilediği sonuçlarına ulaşılmıştır. Enerji tüketiminin bağımlı değişken olduğu model sonuçlarına göre, gelişmiş ülkelerde ekonomik büyüme ve $\mathrm{CO}_{2}$ emisyonunun enerji tüketimini artırdığı, gelişen ülkelerde de yine ekonomik büyüme ve $\mathrm{CO}_{2}$ emisyonunun enerji tüketimini artırdığı, MENA ülkelerinde ise $\mathrm{CO}_{2}$ emisyonunun enerji tüketimini artırırken ekonomik büyümeyi azalttığı tespit edilmiştir.

Bozma vd. (2018) enerji tüketimi ve ekonomik büyüme arasındaki ilişki için 1990-2014 döneminde BRICS ve MINT ülkelerini araştırmışlardır. Panel eş bütünleşme analizinin uygulandığı çalışma sonuçları söz konusu ülkelerde ekonomik büyüme ile enerji tüketiminin eş bütünleşik olduğunu ifade etmektedir.

Shahbaz vd. (2018) enerji tüketimi ile ekonomik büyüme arasındaki ilişkiyi en yüksek enerji tüketen 10 ülke için 1960-2015 döneminde incelemişlerdir. Zaman serisi analiziyle kantil regresyon analizinin kullanıldığ 1 çalışma sonuçlarına göre, ekonomik büyüme ile enerji tüketimi arasında pozitif 
bir ilişki olduğu, Çin, Hindistan, Almanya ve Fransa'da düşük seviyedeki ekonomik büyümenin enerji tüketimi üzerinde zayıf bir etkiye sahip olduğu, ABD, Kanada, Brezilya ve Güney Kore'de yüksek büyüme oranlarında da ekonomik büyümenin enerji tüketimi üzerindeki etkisinin zayıf olduğu tespit edilmiştir.

Bakırtaş ve Akpolat (2018) enerji tüketimi, kentleşme ve ekonomik büyüme arasındaki ilişkiyi 1971-2014 döneminde yeni gelişen piyasa ekonomileri için araştırmışlardır. İki ve üç değişkenli panel nedensellik analizinin ayrı ayrı uygulandığı analiz sonuçları, iki değişkenli analize göre, ekonomik büyümeden enerji tüketimine, kentleşmeden enerji tüketimine ve ekonomik büyümeye doğru nedenselliğin olduğunu, üç değişkenli analize göre ise enerji tüketimi ve kentleşmeden ekonomik büyümeye, ekonomik büyüme ve kentleşmeden enerji tüketimine, enerji tüketimi ve ekonomik büyümeden kentleşmeye doğru nedenselliğin olduğunu göstermektedir.

Gozgor vd. (2018) enerji tüketimi ile ekonomik büyüme arasındaki ilişkiyi 29 OECD ülkesinde 1990-2013 dönemi için incelemişlerdir. Panel ARDL ve kantil regresyon modelinin uygulandığı çalışma sonuçları enerji tüketiminin ekonomik büyümeyi olumlu yönde etkilediğini göstermektedir.

Saidi vd. (2017) enerji tüketimi ile ekonomik büyüme arasındaki ilişkiyi global boyutta 53 ülke üzerinde 1990-2014 döneminde incelemişlerdir. Panel eş bütünleşme ve nedensellik analizinin uygulandığı çalışma sonuçlarına göre ekonomik büyüme ile enerji tüketimi arasında uzun dönemde pozitif ilişkinin olduğu ve çift yönlü nedensellik ilişkisinin varlığı tespit edilmiştir.

Bozkurt ve Yanardağ (2017) enerji tüketimi ile ekonomik büyüme arasındaki ilişkiyi 1971-2011 döneminde gelişmekte olan 19 ülke için değerlendirmişlerdir. Panel eş bütünleşme analizinin uygulandığı çalışma sonuçlarına göre ekonomik büyüme ile enerji tüketiminin eşbütünleşik yani aynı yönlü hareket ettiği tespit edilmiştir.

Çınar ve Yılmazer (2015) yenilenebilir ve yenilenemez enerji kaynakları ile ekonomik büyüme arasındaki ilişkiyi 1990-2013 döneminde gelişmekte olan 8 ülke için araştırmışlardır. Panel ARDL yaklaşımının kullanıldığı analiz sonuçlarına göre büyüme üzerinde yenilenebilir kaynakların yenilenemez kaynaklardan büyüme üzerinde daha fazla etkili olduğu tespit edilmiştir.

Saidi ve Hammami (2015) $\mathrm{CO}_{2}$ emisyonu ve ekonomik büyümenin enerji tüketimi üzerindeki etkisini araştırmışlardır. Avrupa ve Kuzey Asya, Latin Amerika ve Karayipler, Sahra Altı, Kuzey Afrika ve Orta Doğu'yu kapsayan 58 ülkeye ait 1990-2012 dönemi verilerinin kullanıldığı çalışmada GMM tahmincisinden yararlanılmıştır. Panel geneli analiz sonuçlarına göre $\mathrm{CO}_{2}$ emisyonu ve ekonomik büyümenin enerji tüketimini artırdığ tespit edilmiştir. Ayrıca bölgeler bazındaki analiz sonuçları da $\mathrm{CO}_{2}$ emisyonu ve ekonomik 
büyümenin enerji tüketimini artırdığını göstermektedir. $\mathrm{CO}_{2}$ emisyonunun enerji tüketimini artırmasıyla ilgili analiz sonucunun yorumu ekonomik büyüme, emisyon ve enerji tüketiminin birbirini tamamlayıcısı olduğu şeklinde ifade edilmiştir.

Saidi ve Hammami (2015) ve Muhammad (2019)'in belirttiği üzere genel olarak enerji, emisyon ve ekonomik büyüme kapsamındaki literatürün enerji talebi ve/veya tüketiminin ekonomik büyüme üzerindeki etkisi ile ekonomik büyüme ve enerji tüketiminin sera gazı emisyonu üzerindeki etkisi çerçevesinde yoğunlaşmıştır. Ekonomik büyüme ve sera gazı emisyonlarının enerji tüketimini nasıl etkilediği noktasında literatürde yer alan çalışmaların sayısı azdır. Bu çerçevede çalışma ekonomik büyüme, sera gazı emisyonu ve ticari açıklığın enerji tüketimi üzerine etkisini G7 ülkeleri kapsamında inceleyerek literatüre katkı sağlamayı amaçlamaktadır.

\section{Veri Seti ve Yöntem}

Enerji tüketimi ile ekonomik büyüme arasındaki ilişkinin incelendiği bu çalışmada G7 ülkelerine ait 1993-2018 dönemine ilişkin veriler kullanılmıştır. Bağımlı değişken olarak enerji tüketiminin alındığ 1 çalışmada ticari dışa açıklık, ekonomik büyüme ve sera gazı emisyonları bağımsız değişken olarak analize dahil edilmiştir. Panel veri analizinin uygulandığı çalışmada verilere ilişkin detaylı bilgiler Tablo 1'de yer almaktadır.

Tablo 1. Veri Seti

\begin{tabular}{llll}
\hline Değişken kodu & Değişken adı & Açıklama & Kaynak \\
\hline LENERGY & Enerji tüketimi & Toplam nihai tüketim (ktoe) & IEA \\
\hline LTO & Ticari açıklık & $\begin{array}{l}\text { İthalat ve ihracat toplamının } \\
\text { GSYH'e oranı }\end{array}$ & WDI \\
\hline LGHG & Sera gazı emisyonu & İndeks 2000=100 (LULUCF) & OECD \\
\hline LGDPPC & Kişi başına GSYH & Kişi başına GSYH & WDI
\end{tabular}

Logaritmik formdaki verilerle enerji tüketimi, ticari açıklık, sera gazı emisyonu ve ekonomik büyüme arasındaki ilişki için kurulan model Denklem 1 'de yer almaktadir:

$L E N E R G Y_{i t}=\alpha_{i t}+\beta_{1} L T O_{i t}+\beta_{2} L G H G_{i t}+\beta_{3} L G D P P C_{i t}+\varepsilon_{i t}$

Denklem 1'de i ülkeleri, $\alpha$ sabit değeri t zamanı ve $\varepsilon$ hata terimini ifade etmektedir. Değişkenlere ait tanımlayıcı istatistikler Tablo 2'de yer almaktadır.

Tablo 2. Tanımlayıcı İstatistikler

\begin{tabular}{llllll}
\hline $\begin{array}{l}\text { Değişken } \\
\text { kodu }\end{array}$ & $\begin{array}{l}\text { Gözlem } \\
\text { sayı1s1 }\end{array}$ & Ortalama & $\begin{array}{l}\text { Standart } \\
\text { sapma }\end{array}$ & Minimum & Maksimum \\
\hline LENERGY & 182 & 5.472186 & 0.344915 & 5.063036 & 6.202524 \\
LTO & 182 & 49.66962 & 18.37205 & 16.01388 & 88.59639 \\
LGHG & 182 & 1.975724 & 0.0396377 & 1.813247 & 2.039692 \\
LGDPPC & 182 & 4.60883 & 0.057296 & 4.461856 & 4.739042 \\
\hline
\end{tabular}


Analiz sonuçlarının güvenilir olması yani sahte regresyon sorununun olmaması için serilerin durağanlığı önem arz etmektedir. Panel veri analizinde serilerin durağanlığ 1 birinci ve ikinci kuşak birim kök testleriyle sınanabilmektedir. Birinci ve ikinci kuşak birim kök testleri arasında seçim yapabilmek için birimler arası korelasyon testlerinden yararlanılır. Serilerde birimler arası korelasyon olması durumunda ikinci kuşak, olmaması durumunda ise birinci kuşak birim kök testleri kullanılır. Birimler arası korelasyon için çeşitli testler kullanılabilmekle birlikte zaman $(\mathrm{T})$ boyutunun birim $(\mathrm{N})$ boyutundan büyük olması durumunda temel hipotezi $\mathrm{H}_{0}: \operatorname{cov}\left(\mathrm{u}_{\mathrm{it}}, \mathrm{u}_{\mathrm{ji}}\right)=\mathrm{p}_{\mathrm{ij}}=0$ olmak üzere tüm $t$ değerleri için $i \neq j$ eşitsizliği geçerlidir $\left(u_{i t}\right.$ ile $u_{j t}$ arasındaki kovaryansın sıfır olması yani kalıntıların birimlerarası korelasyon içermemesi) şeklinde olan Breusch Pagan (1980) LM testi uygun olmaktadır. Breusch-Pagan (1980) tarafindan geliştirilen öncü nitelikteki birimler arası korelasyon testi Lagrange Multiplier (LM) testi ve Pesaran vd. (2008) tarafindan geliştirilen Düzeltilmiş (Adjusted) LM ( $\mathrm{LM}_{\mathrm{adj}}$ ) test istatistikleri aşağıdaki gibidir:

$$
\begin{aligned}
& L M=T \sum_{i=1}^{N-1} \sum_{j=i+1}^{N} \hat{p}_{i j}^{2} \sim X_{N(N-1) / 2}^{2} \\
& L M_{a d j}=\sqrt{\left(\frac{2}{N(N-1)}\right) \sum_{i=1}^{N-1} \sum_{j=i+1}^{N}\left[\hat{p}_{i j}^{2}\left(\frac{(T-k) \hat{p}_{i j}^{2}-\mu_{T i j}}{\vartheta_{T i j}}\right)\right] \sim N(0,1)}
\end{aligned}
$$

Birimler arası korelasyonun varlığı tespit edildikten sonra serilerin durağanlığının tespiti için ikinci kuşak birim kök testlerinden yararlanılır. Pesaran (2007) çalışmasında Pesaran CADF (yatay kesit genişletilmiş Dickey Fuller) birim kök testinin birim ve zaman boyutunda büyüklük farketmeksizin geçerli olduğunu göstermiştir. CADF testinde sıfir hipotezi $H_{0}: \beta_{i}=0$ tüm i'ler için geçerlidir. Alternatif hipotez ise $H_{1}: \beta_{i}<0$ olmak üzere $\mathrm{i}=1,2, \ldots \mathrm{N}_{\mathrm{i}}$ ve $\beta_{i}=0$, $\mathrm{i}=\mathrm{N}_{1}+2, \ldots \mathrm{N}$ olarak ifade edilir. Pesaran CADF birim kök testi t değeri Denklem 4 'te yer almaktadır:

$t_{1}(N, T)=\frac{\Delta Y_{i}^{\prime} \bar{M}_{w} Y_{i-1}}{\hat{\sigma}\left(Y_{i-1}^{\prime} \bar{M}_{w} Y_{i-1}\right)^{1 / 2}}$

CADF testi sonucunda elde edilen değer CIPS (yatay kesit genişletilmiş Im, Pesaran ve Shin) istatistiği olarak adlandırılmakta ve CADF testi ile hesaplanan her bir birime ait $t$ değerlerinin ortalaması alınarak elde edilmektedir. CIPS test istatistiği Denklem 5'te yer almaktadır:

CIPS $=N^{-1} \sum_{\mathrm{i}=1}^{N} C A D F_{i}$ 
CIPS test istatistiği farklı $\mathrm{N}$ ve $\mathrm{T}$ değerleri için $\% 1, \% 5$ ve $\% 10$ anlamlılık seviyesine göre hesaplanarak Pesaran (2007)'de tablo halinde sunulmuştur. CIPS test istatistiğinin mutlak değer olarak kritik değerlerden büyük olması serilerin durağan olduğu anlamına gelmektedir.

Serilerin durağanlık tespitinden sonra uygulanacak eş bütünleşme testine karar verebilmek için sabit ve eğim parametrelerinin homojen mi yoksa heterojen mi olduğunun bilinmesi gerekmektedir. Swamy (1970) tarafından geliştirilen Swamy S homojenlik testi havuzlanmış tahminciler aracılığı ile her bir eğim parametre tahminlerinin dağılımını hesaplamaktadır (Ando ve Bai, 2015:114). Boş hipotezin $H_{0}: \beta_{1}=\beta$ eğim katsayılarının homojen olduğunu belirten, alternatif hipotezin ise $H_{1}: \beta_{i} \neq \beta$ ise eğim katsayılarının heterojen olduğunu ileri süren Swamy $S$ test istatistiği Denklem 6'da yer almaktadır:

$\hat{S}=\chi_{k(N-1)}^{2}=\sum_{i=1}^{N}\left(\hat{\beta}_{i}-\bar{\beta}^{*}\right)^{\prime} \hat{V}_{i}^{-1}\left(\hat{\beta}_{i}-\bar{\beta}^{*}\right)$

Seriler arasında eş bütünleşme yani uzun dönemli ilişkinin varlığının tespiti için birinci ve ikinci kuşak eşbütünleşme testleri yapılabilmektedir. Söz konusu kuşakların tespiti, seriler arasında birimler arası korelasyonun olup olmaması ile sabit ve eğim parametrelerindeki homojenlik/heterojenlik açısından değerlendirilmektedir. Eğer serilerde birimler arası korelasyon mevcut ve parametreler heterojen ise ikinci kuşak eşbütünleşme testlerinin kullanılması uygun olmaktadır. Çalışmada birimler arası korelasyonun mevcut olması ve eğim ve sabit parametrelerinin heterojen olması nedeniyle ikinci kuşak eşbütünleşme testlerinden olan Gengenbach, Urbain ve Westerlund panel eşbütünleşme testinden yararlanılmıştır. Gengenbach, Urbain ve Westerlund (2016) tarafindan geliştirilen bu test hata düzeltme modelli olup, birimler arası korelasyon ve heterojenlik durumlarında kullanılabilmektedir. Test istatistiği Denklem 7'de birimlere ait test istatistiklerinin ortalaması olan panel test istatistiği ise Denklem 8'de yer almaktadır:

$t_{c_{i}}=t_{\alpha_{y i}}=\frac{\hat{\alpha}_{y_{i}}}{\hat{\sigma}_{\widehat{\alpha}_{y_{i}}}}$

$\bar{t}_{c}=\frac{1}{N} \sum_{\mathrm{I}=1}^{N} t_{c_{i}}$

$H_{0}: \alpha_{y_{i}}=\ldots=\alpha_{y_{N}}=0$ şeklinde kurulan sıfir hipotezi eşbütünleşme ilişkisinin olmadığını gösterirken alternatif hipotez $H_{1}: \alpha_{y_{i}}<0$ ise en az bir birim için eşbütünleşme ilişkisinin varlığını doğrulamaktadır.

Eş bütünleşme testinin ardından serilerin eş bütünleşik olduğuna karar verilmişse, uzun dönemli ilişkinin tahmini için çeşitli yöntemler kullanılmaktadır. Söz konusu yöntemler birimler arası korelasyonun varlığı ve parametrelerin homojenliğine göre belirlenmektedir. Çalışmada birimler arası 
korelasyonun olması ve parametrelerin heterojen olması sebebiyle ikinci kuşak heterojen tahminci olan ve Pedroni (2001) tarafindan geliştirilen ortalama grup dinamik en küçük kareler DOLSMG yöntemi kullanılmıştır. Son olarak uzun ve kısa dönemli ilişkinin tahmini için yani panel hata düzeltme modeli için genişletilmiş ortalama grup tahmincisi (AMG) yöntemi kullanılmıştır. Değişkenler arasında uzun dönemli ilişkinin varlığı tespit edilmişse, uzun ve kısa döneme ait ilişkiler tahmin edilebilmektedir. Panel hata düzeltme temelli modellerin tahmini birimler arası korelasyonu dikkate alıp almaması kriterine göre birinci kuşak ve ikinci kuşak olarak iki gruba ayrılmaktadır. Bond ve Eberhardt (2009) ile Eberhardt ve Teal (2010) tarafından geliştirilen AMG tahmincisi birimler arası korelasyon ve heterojenlik durumunda kullanılabilmektedir (Tatoğlu, 2018, 269-270). Bu yöntemde hata düzeltme modeli ilk olarak T-1 adet zaman gölge değişkeni eklenerek ve birinci farklar alınarak tahmin edilmektedir (Tatoğlu, 2018, 303):

$\Delta Y_{i t}=b^{\prime} \Delta X_{i t}+\sum_{t=2}^{T} c_{t} \Delta D_{t}+e_{i t} \quad \rightarrow \hat{c}_{t} \equiv \hat{\mu}_{t}^{*}$

Daha sonra tahminler her bir birim için kurulan hata düzelteme modeline eklenmekte:

$Y_{i t}=a_{i}+b_{i}^{\prime} X_{i t}+c_{i} t+d_{i} \hat{\mu}_{t}^{*}+e_{i t}$

Son olarak birimler bazında ortalama alınarak ve Pesaran ve Smith (1995) MG yaklaşımıyla AMG tahmincisine ulaşılmaktadır (Tatoğlu, 2020, 82):

$\hat{b}_{A M G}=N^{-1} \sum_{i} \hat{b}_{i}$

\section{Analiz Sonuçları}

Enerji tüketimi ile ekonomik büyüme, ticari açıklık ve sera gazı emisyonu arasındaki ilişki için kurulan modelde ilk olarak birimler arası korelasyon testi yapılmıştır. Breusch Pagan (1980) LM testi ile gerçekleştirilen test sonuçları Tablo 3'te yer almaktadir:

Tablo 3: Birimler Arası Korelasyon Testi Sonuçları

\begin{tabular}{lll}
\hline Test & İstatistik & Olasllk değeri \\
\hline Breusch Pagan (1980) LM & 71.05 & $0.0000^{*}$ \\
\hline Pesaran vd. (2008) LM adj $^{*}$ & 18.64 & $0.0000^{*}$ \\
\hline
\end{tabular}

*\%1 anlamll11k düzeyini göstermektedir.

Tablo 3'te yer alan sonuçlara göre $\mathrm{H}_{0}$ hipotezi reddedilerek birimler arası korelasyonun var olduğu tespit edildikten sonra ikinci kuşak birim kök testlerinin uygulanmasına karar verilmiştir. İkinci kuşak panel birim kök testlerinden ve 
Pesaran (2007) tarafından geliştirilen CIPS test istatistiği sonuçları Tablo 4'te yer almaktadır:

Tablo 4. Birim Kök Testi Sonuçları

\begin{tabular}{lcccccc} 
& \multicolumn{7}{c}{ Düzey değerleri } \\
Değisskenler & t-bar & cv10 & cv5 & cv1 & Z[t-bar] & P değeri \\
\hline LENERGY & -1.323 & -2.210 & -2.330 & -2.570 & 1.193 & 0.884 \\
\hline LTO & -1.881 & -2.210 & -2.330 & -2.570 & -0.329 & 0.371 \\
LGHG & -2.212 & -2.210 & -2.330 & -2.570 & -1.232 & 0.109 \\
\hline LGDPPC & -1.762 & -2.210 & -2.330 & -2.570 & -0.007 & 0.497 \\
\hline \multicolumn{7}{c}{ Fark değerleri } \\
\hline LENERGY & -4.477 & -2.210 & -2.330 & -2.570 & -7.412 & $0.000^{*}$ \\
\hline LTO & -3.292 & -2.210 & -2.330 & -2.570 & -4.179 & $0.000^{*}$ \\
\hline LGHG & -3.877 & -2.210 & -2.330 & -2.570 & -5.775 & $0.000^{*}$ \\
LGDPPC & -2.308 & -2.210 & -2.330 & -2.570 & -1.496 & $0.067^{* *}$ \\
\hline
\end{tabular}

*, *** sirasıyla $\% 1$ ve $\% 10$ anlamlılık düzeyini belirtmektedir.

Tablo 4'te yer alan 1 gecikme uzunluğu durumunda CIPS birim kök testi sonuçlarına göre tüm değișkenlere ait düzey değerlerinin mutlak değer olarak kritik değerlerden küçük olması nedeniyle durağan olmadıkları, birinci farklarında ise kritik değerlerden büyük olması nedeniyle durağan hale geldikleri görülmektedir. Eş bütünleşme testinin belirlenmesi amacıyla uygulanan homojenlik testi sonuçları Tablo 5'te yer almaktadır:

Tablo 5. Homojenlik Testi Sonuçları

\begin{tabular}{lcc}
\hline & İstatistik & Olasılık değeri \\
\hline$\hat{\Delta}$ & 10.855 & $0.000^{*}$ \\
\hline$\widehat{\Delta}_{\text {adj }}$ & 12.079 & $0.000^{*}$ \\
\hline$* \% 1$ anlamlllık düzeyini belirtmektedir. & &
\end{tabular}

Tablo 5'te yer alan sonuçlar sabit ve eğim parametrelerinin heterojen olduğunu göstermektedir. Birimler arası korelasyonun varlı̆̆ 1 ve heterojenlik durumunda kullanılması uygun olan eş bütünleşme testlerinden biri de Gengenbach, Urbain ve Westerlund (2016) eş bütünleşme testidir. Eş bütünleşme testinin ardından uzun dönemli ilișkinin tahmini için birimler arası korelasyonun olması ve parametrelerin heterojen olması sebebiyle ikinci kuşak heterojen tahmincisi olan ve Pedroni (2001) tarafindan geliștirilen ortalama grup dinamik en küçük kareler DOLSMG yöntemi kullanılmıştır. Analiz sonuçları Tablo 6'da yer almaktadir:

Tablo 6. Eş Bütünleşme Ve Uzun Dönemli İlişki Tahmini Sonuçları

\begin{tabular}{|c|c|c|c|}
\hline d.y & Katsay 1 & T-bar & p-value \\
\hline$y(t-1)$ & $-0.822 *$ & -4.115 & $<0.01$ \\
\hline \multicolumn{4}{|c|}{ DOLSMG Tahmincisi sonuçları } \\
\hline LENERGY & Coef. & & t-stat \\
\hline LTO & -0.002 & & $-9.111^{*}$ \\
\hline LGHG & -0.022 & & $15.82 *$ \\
\hline LGDPPC & -0.491 & & $-7.701 *$ \\
\hline
\end{tabular}

*\%1 anlaml1lık düzeyini belirtmektedir. 
Tablo 6'da yer alan sonuçlara göre, bağımlı değişkenin gecikmeli değeri olan y(t-1) değeri $(<0.01)$ olduğundan dolayı bağımlı değişken ile bağımsız değiş̧kenler arasında eş bütünleşme ilişkisinin olduğu kabul edilmektedir. Ayrıca DOLSMG sonuçları göre, uzun dönem $\mathrm{t}$ istatistiği anlamlıdır [ $(\mathrm{N} * \mathrm{~T}-\mathrm{k}=169)$ için t tablo değeri $\alpha=0.01$ için 2.62 'dir.] ve uzun dönemde ticari açıklık, sera gazı emisyonu ve ekonomik büyüme enerji tüketimini negatif yönlü etkilemektedir. Son olarak, uzun ve kısa dönemli ilişkinin tahmini için kullanılan genişletilmiş ortalama grup tahmincisi AMG yöntemi sonuçları Tablo 7'de yer almaktadır:

Tablo 7. Uzun ve Kısa Dönemli İlişki İçin AMG Tahmincisi Sonuçları

\begin{tabular}{lccl}
\hline LENERGY & Katsay1 & t-stat & p-value \\
\hline LTO & -0.0001 & -0.56 & 0.576 \\
\hline LGHG & 0.5568 & 3.80 & $0.000^{*}$ \\
\hline LGDPPC & 0.1664 & 1.82 & $0.069^{* * *}$ \\
\hline \multicolumn{4}{c}{ Diğer İstatistikler } \\
\hline Hata düzeltme katsayıs1 & -0.70 & -5.58 & $0.000^{*}$ \\
\hline Wald t-stat & 96.89 & & \\
\hline Wald p-value & 0.0000 &
\end{tabular}

Tablo 7'de yer alan sonuçlara göre, ticari açıklığın istatistiksel olarak anlamsız olduğu, sera gazı emisyonundaki artışın enerji tüketimini artırdığı ve son olarak ekonomik büyümedeki artışın enerji tüketimini artırdığı tespit edilmiştir. Hata düzeltme katsayısı negatif ve anlamlıdır. Bu sonuç bir dönemde oluşan dengesizliklerin bir sonraki dönemde düzeleceğini ifade etmektedir.

\section{Sonuç ve Değerlendirme}

Uluslararası düzlemde ülkelerin rekabet gücü kazanmaları, pazar payı elde etmeleri ve dolayısıyla ekonomik kalkınmalarını gerçekleştirebilmeleri açısından enerji faktörü önemli bir girdi olmuştur. Enerji tüketimi ile ekonomik büyüme arasındaki ilişkinin varlığı ve iliş̧kinin istatistiksel yönü ekonomi literatürünü oldukça meşgul etmektedir. İki unsur arasında analiz sonuçlarına göre hipotezler oluşturulmuş ve ampirik çalışmalar bu hipotezler çerçevesinde değerlendirilmiştir. Enerji tüketiminin ekonomik büyümeyi artırması büyüme hipotezi, ekonomik büyümedeki artışın enerji tüketimini artırması koruma hipotezi, enerji tüketiminin ekonomik büyüme üzerinde herhangi bir etkisinin olmaması durumu tarafsızlık hipotezi ve enerji tüketimi ile ekonomik büyümenin birbirine bağlım olması durumu ise geri besleme hipotezi olarak değerlendirilmiştir.

Enerji tüketimi, ekonomik büyüme, ticari açıklık ve sera gazı emisyonu arasındaki ilişkinin araştırıldığı bu çalışmada 1993-2018 döneminde G7 ülkeleri incelenmiştir. Önsel testlerin neticesinde yapılan eşbütünleşme analizi sonucuna göre, enerji tüketimi ile tüm bağımsız değişkenler arasında eş bütünleşme ilişkisinin olduğu tespit edilmiştir. Uzun ve kısa dönemli ilişki açısından 
değerlendirildiğinde sera gazı emisyonu ve ekonomik büyüme ile enerji tüketimi arasında pozitif yönlü ilişkinin olduğu yani sera gazı emisyonu ve ekonomik büyümedeki artışların enerji tüketimini artırdığı sonucuna varılmıştır. Ekonomik büyümenin enerji tüketimini pozitif yönlü etkilemesi literatürde yer alan koruma hipotezini desteklemektedir. Saidi ve Hammami (2015) ve Muhammad (2019) çalışma sonuçlarıyla örtüşen sera gazı emisyonunun enerji tüketimini artırmasına ilişkin analiz sonucu ekonomik büyüme, emisyon ve enerji tüketiminin birbirinin tamamlayıcısı olduğu şeklinde ifade edilmektedir. Emisyon, ekonomik büyümenin bir göstergesi olarak kabul edildiğinde emisyondaki artışın enerji tüketimini artırması ekonomik büyüme kaynaklı olduğu söylenebilir.

Sanayi devrimiyle birlikte oldukça önem kazanan enerji faktörünün günümüzde ve gelecekte de üretim için en önemli girdiyi oluşturacağı düşünülmektedir. Ülkelerin enerji verimliliğini dikkate almalarının yanında fosil yakıt tükenen bir enerji kaynağı olması dolayısıyla ülkelerin yenilenebilir enerji kaynaklarına yönelmeleri günümüz ve gelecek için politika yapıcıları açısından önem arz etmektedir. Ayrıca, fosil yakıt kaynaklı enerji tüketiminin neden olduğu sera gazı emisyonlarının sonucu olan küresel ısınma ve iklim değişikliği hususu da dikkate alınmalıdır. Enerji tüketimi, ekonomik büyüme ve sera gazı emisyonu döngüsünde ekonomik büyüme kaynaklı emisyonun azaltılması noktasında çevresel inovasyonları geliştirici politika uygulamaları önem arz etmektedir.

\section{Kaynaklar}

Altiner A. (2019). MINT Ülkelerinde Enerji Tüketimi ve Ekonomik Büyüme İlişkisi: Panel Nedensellik Analizi. Gümüşhane Üniversitesi Sosyal Bilimler Enstitüsü Elektronik Dergisi, 10(2), 369-378.

Ando, T. ve Bai, J. (2015). A simple new test for slope homogeneity in panel data models with interactive effects. Economics Letters, Elsevier, 136(C), 112-117.

Apergis, N. ve Panye, J.E. (2009). Energy consumption and economic growth in central America: evidence from a panel cointegration and error correction model. Energy Economics, 31, 211-216.

Bakırtaş, T. ve Akpolat, A.G. (2018). The relationship between energy consumption, urbanization, and economic growth in new emergingmarket countries. Energy, 147, 110-121.

Bond, S.R. ve Eberhardt, M. (2009). Cross-Section Dependence in Nonstationary Panel Models: A Novel Estimator. Nordic Econometrics Meeting, Sweeden. 
Bozkurt, K. ve Yanardağ, M.Ö. (2017). Enerji Tüketimi ve Ekonomik Büyüme: Gelişmekte Olan Ülkeler İçin Bir Panel Eşbütünleşme Analizi. Yönetim ve Ekonomi Araştırmaları Dergisi, 15, 194-213.

Bozma, G., Aydın, R. ve Kolçak, M. (2018). BRICS ve MINT Ülkelerinde Ekonomik Büyüme ve Enerji Tüketimi İlişkisi. Iğdır Üniversitesi Sosyal Bilimler Dergisi, 15, 323-338.

Breusch, T. ve Pagan, A. (1980). The Lagrange Multiplier Test and Its Applications to Model Specification in Econometrics. Review of Economic Studies, 47(1), 239-253.

Canh, N.P., Schinckus, C., Thanh, S.D. ve Chong, F.H.L. (2021). The determinants of the energy consumption: A shadow economybased perspective. Energy, 225, 1-14.

Çınar, S. ve Yılmazer, M. (2015). Yenilenebilir Enerji Kaynaklarının Belirleyicileri ve Ekonomik Büyüme İlişkisi: Gelişmekte Olan Ülkeler Örneği. Dokuz Eylül Üniversitesi İktisadi ve İdari Bilimler Fakültesi Dergisi, 30(1), 55-78.

Eberhardt, M. ve Teal, F. (2010). Productivity Analysis in Global Manufacturing Production. Department of Economics, University of Oxford, WP.

Ebohon, O.J., 1996. Energy, economic growth and causality in developing countries: a case study of Tanzania and Nigeria. Energy Policy,24, 447453.

Erdoğan, S., Gedikli, A., Demir Yılmaz, A., Haider, A. ve Zafar, M.W. (2020). Investigation of energy consumption-Economic growth nexus: A note on MENA sample. Energy Reports, 5, 1281-1292.

Gengenbach, C., Urbain, J. ve Westerlund, J. (2016). Error Correction Testing in Panels with Common Sthocastic Trends. Journal of Applied Econometrics, 31, 982-1004.

Gozgor, G., Lau, C.K.M. ve Lu, Z. (2018). Energy consumption and economic growth: New evidence from the OECD countries. Energy, 153, 27-34.

Kahouli, B. (2019). Does static and dynamic relationship between economic growth and energy consumption exist in OECD countries?. Energy Reports, 5, 104-116.

Konak, A. (2020). G-7 Ülkelerinde İhracatın Ekonomik Büyüme Üzerindeki Etkisi: Panel Nedensellik Analizi. Bartın Üniversitesi İktisadi ve İdari Bilimler Fakültesi Dergisi, 11 (21), 232-251. 
Muhammad, B. (2019). Energy consumption, CO2 emissions and economic growth in developed, emerging and Middle East and North Africa countries. Energy, 179, 232-245.

Pedroni, P. (2001). Purchasing Power Parity Tests in Cointegrated Panels. The Review of Economics and Statistics, 83 (4), 727-731.

Pesaran, M. H. (2007). A simple panel unit root test in the presence of crosssection dependence. Journal of Applied Econometrics, 22(2), 265-312.

Pesaran, M.H. ve Smith, R.P. (1995). Estimating Long-Run Relationship from Dynamic Heterogeneous Panels. Journal of Econometrics, 68, 79-113.

Pesaran, M.H., Ullah, A. \& Yamagata, T. (2008). A bias-adjusted LM test of error crosssection independence. Econ J, 11 (1), 105-127.

Rahman M.M. (2021) The dynamic nexus of energy consumption, international trade and economic growth in BRICS and ASEAN countries: A panel causality test. Energy, 229, 1-10.

Sadorsky, P. 2012. Energy Consumption, Output and Trade in South America, Energy Economics. 34, 476-488.

Saidi K. ve Hammami S. (2015). The impact of $\mathrm{CO}_{2}$ emissions and economic growth on energy consumption in 58 countries. Energy Reports, 1, 6270.

Saidi, K., Rahman, M.M. ve Amamri, M. (2017). The causal nexus between economic growth and energy consumption: New evidence from global panel of 53 countries. Sustainable Cities and Society, 33, 45-56.

Shahbaz, M., Zakaria, M., Shahzad, S.J.H. ve Mahalik, M.K. (2018). The energy consumption and economic growth nexus in top ten energyconsuming countries: Fresh evidence from using the quantile-on-quantile approach. Energy Economics, 71, 282-301.

Squalli, J., 2007. Electricity consumption and economic growth: bounds and causality analyses of OPEC countries. Energy Economics, 29, 11921205.

Swamy, P. (1970). Efficient Inference in A Random Coefficient Regression Model. Econometrica, 38(2), 311-322.

Sweeney, J.L. (2000). Economics of Energy. Stanford University, 4(9), 1-28.

Tatoğlu, F.Y. (2020). İleri Panel Veri Analizi Stata Uygulamalı 4. Baskı, Beta, İstanbul.

Templet, P.H., 1999. Energy, diversity and development in economic systems: an empirical analysis. Energy Policy, 30, 223-233. 